\title{
Defensive medicine in neurosurgery: the Canadian experience
}

\author{
Timothy R. Smith, MD, PhD, MPH, ${ }^{1}$ M. Maher Hulou, MD, ${ }^{1}$ Sandra C. Yan, BS, BA, ${ }^{1}$ \\ David J. Cote, BS, ${ }^{1}$ Brian V. Nahed, MD, MSc, ${ }^{2}$ Maya A. Babu, MD, MBA, ${ }^{3}$ Sunit Das, MD, PhD, ${ }^{4}$ \\ William B. Gormley, MD, MPH, ${ }^{1}$ James T. Rutka, MD, PhD, FRCSC, ${ }^{4}$ Edward R. Laws Jr., MD, ${ }^{1}$ and \\ Robert F. Heary, MD ${ }^{5}$
}

\begin{abstract}
'Department of Neurosurgery, Brigham and Women's Hospital, Harvard Medical School; 2Department of Neurosurgery, Massachusetts General Hospital, Harvard Medical School, Boston, Massachusetts; ' $D$ Department of Neurological Surgery, Mayo Medical School, Rochester, Minnesota; ${ }^{4}$ Division of Neurosurgery, Department of Surgery, University of Toronto, Ontario, Canada; and ${ }^{5}$ Department of Neurological Surgery, Rutgers New Jersey Medical School, Newark, New Jersey
\end{abstract}

OBJECTIVE Recent studies have examined the impact of perceived medicolegal risk and compared how this perception impacts defensive practices within the US. To date, there have been no published data on the practice of defensive medicine among neurosurgeons in Canada.

METHODS An online survey containing 44 questions was sent to 170 Canadian neurosurgeons and used to measure Canadian neurosurgeons' perception of liability risk and their practice of defensive medicine. The survey included questions on the following domains: surgeon demographics, patient characteristics, type of physician practice, surgeon liability profile, policy coverage, defensive behaviors, and perception of the liability environment. Survey responses were analyzed and summarized using counts and percentages.

RESULTS A total of 75 neurosurgeons completed the survey, achieving an overall response rate of $44.1 \%$. Over onethird (36.5\%) of Canadian neurosurgeons paid less than $\$ 5000$ for insurance annually. The majority (87\%) of Canadian neurosurgeons felt confident with their insurance coverage, and $60 \%$ reported that they rarely felt the need to practice defensive medicine. The majority of the respondents reported that the perceived medicolegal risk environment has no bearing on their preferred practice location. Only 1 in 5 respondent Canadian neurosurgeons (21.8\%) reported viewing patients as a potential lawsuit. Only $4.9 \%$ of respondents would have selected a different career based on current medicolegal risk factors, and only $4.1 \%$ view the cost of annual malpractice insurance as a major burden.

CONCLUSIONS Canadian neurosurgeons perceive their medicolegal risk environment as more favorable and their patients as less likely to sue than their counterparts in the US do. Overall, Canadian neurosurgeons engage in fewer defensive medical behaviors than previously reported in the US.

http://thejns.org/doi/abs/10.3171/2015.6.JNS15764

KEY WORDS defensive medicine; Canada; malpractice; liability; neurosurgery

$\mathrm{D}$ EFENSIVE medicine (DM) is defined as a deviation from regular medical practice because of medicolegal fears. ${ }^{16,18}$ DM presents in 2 forms: 1 ) assurance behavior, or positive DM, which involves supplementing additional medical services for fear of liability risk and thereby deterring patients from filing malpractice claims; and 2) avoidance behavior, or negative DM, which reflects the physicians' efforts to distance themselves from a potential lawsuit. ${ }^{15-17}$ In 1 study, assurance behavior was found to be more prevalent in emergency physicians (59\%) in comparison with other physicians in high-risk specialties, whereas avoidance behavior was less practiced by emergency physicians $(17 \%)$ in comparison with orthopedic surgeons (39\%). ${ }^{16}$ The practice of 
DM contributes to rising health care costs, and the estimate of excess health expenditures due to DM is roughly $\$ 60.2$ billion per year. ${ }^{14}$ Thus, malpractice health debates have often focused on the movement of providers toward a cost-effective system by reducing the practice of DM. This, however, is difficult because it requires the shifting of motivations. Did the physician order a certain test to avoid litigation, or was there some other motivation unrelated to legal fears (e.g., reimbursement)?

Historically, there have been several approaches to estimating the cost of tort reform and, thus, DM by extension. The most common sources of data used to assess DM costs include direct physician surveys, ${ }^{10}$ medical record analyses, ${ }^{4}$ malpractice insurance premium rates, malpractice claims paid out, Medicare data across various liability risk groups, and the percentages of overall legal costs for tort cases..$^{13}$

In this paper, we studied the Canadian health care system and, more specifically, the neurosurgeons practicing within it. The impact of perceived medicolegal risk was surveyed, as well as any potential correlation with DM practices in neurosurgery in Canada. This paper can be regarded as one of the first steps to comparing the practice of DM internationally.

\section{Methods \\ Study Design}

An online survey containing 44 questions on DM was used to measure Canadian neurosurgeons' perception of liability risk and their practice of DM (see Appendix). The questionnaire was developed with input from numerous societies within neurosurgery (the Canadian Neurological Society, the American Association of Neurological Surgeons, the American Board of Neurological Surgery, the Congress of Neurological Surgeons, the Society of Neurological Surgeons, the Neurosurgical Society of America, the Society of University Neurosurgeons, the Council of State Neurosurgical Societies, and the Illinois State Neurosurgical Society).

The survey included questions on 8 domains: surgeon demographics, patient characteristics, type of physician practice, insurance type, surgeon liability profile, reimbursement, defensive behaviors, and perception of the liability environment.

\section{Study Procedures}

This study involved an online survey of 44 questions. This survey took, on average, less than 10 minutes to complete. The survey was entirely confidential and open to responders for 60 days.

\section{Statistical Analysis}

Survey data were collected anonymously and analyzed using IBM SPSS version 22 (IBM, Inc.). Basic patient demographics were summarized using counts and percentages for nominal variables and means, medians, and standard deviations/ranges for continuous variables.

\section{Results}

Seventy-five of the 170 Canadian neurosurgeons reg- istered in the directory of the Canadian Neurological Society completed the questionnaire (thereby achieving a $44.1 \%$ response rate), and $85.2 \%$ and $9.4 \%$ of respondents were male or female neurosurgeons, respectively. In total, 27.4\% of neurosurgeons were younger than 40 years, whereas $40.5 \%$ of the participating physicians were between 40 and 60 years of age. Neurosurgeons from every Canadian province participated in this survey, with the majority (41.9\%) living in Ontario. Almost $70 \%$ of respondents reported that the majority of their patients were classified as Caucasian. In terms of medical experience, $25.7 \%$ of the participating physicians had 10 to 20 years of experience in neurosurgery. Only $21.6 \%$ were still in neurosurgery training, including residency or fellowship, and at least $27 \%$ had more than 20 years of experience in neurosurgery (Table 1).

The largest percentage of respondents was in academic practice (77\%), with the vast majority practicing either spine surgery $(43.2 \%)$ or general neurosurgery (45.9\%). At least $10 \%$ were practicing in a community setting or academic affiliate, and $6.7 \%$ of the respondents were retired. In total, $27 \%$ of the neurosurgeons were in trauma neurosurgery, $16.2 \%$ were practicing functional neurosurgery, $23 \%$ were cerebrovascular neurosurgeons, $30 \%$ were operating on tumors, and $25.7 \%$ were also operating on the pediatric population (Table 2 ). In total, $35 \%$ of the neurosurgeons operated on 200 to 300 patients annually, and almost the same number of neurosurgeons operated on 100 to 200 cases annually. Only 5.4\% operated on fewer than 50 cases per year, while $2.7 \%$ operated on more than 500 cases per year. The number of lifetime operations was also surveyed and found to be almost equally distributed among our groups. Of note, $14.9 \%$ of neurosurgeons had operated on 5000 to 10,000 patients throughout their lives (Table 1).

The average annual cost of indemnity insurance was $\$ 19,600$ (SD $\$ 11,900$ in 2014 USD). Almost $65 \%$ of the respondents reported that less than $5 \%$ of their income goes to malpractice insurance, almost $20 \%$ spent around $6 \%$ to $10 \%, 5.4 \%$ spent $10 \%$ to $19 \%$, and only $1.4 \%$ reported that $20 \%$ to $29 \%$ of their income goes to malpractice coverage. Interestingly, over $50 \%$ of the neurosurgeons reported that liability insurance is not a burden at all and that the liability premiums have not significantly changed in the last 3 years. However, $4.1 \%$ of neurosurgeons reported current liability insurance to be a major burden (Tables 3 and 4). The cost of liability insurance was also surveyed. In total, $16.2 \%$ paid less than $\$ 1000,20.3 \%$ paid $\$ 1000$ to $\$ 5000$, and $4 \%$ paid $\$ 5000$ to $\$ 10,000$. Interestingly, the majority $(25.7 \%)$ still paid more than $\$ 30,000$ (Table 3).

The level of confidence in malpractice insurance was found to be 1 of the 2 most important predictors of DM behavior. In Canada, $74.3 \%$ of surveyed neurosurgeons were "very" confident in their coverage, and only $1.4 \%$ answered "not at all" when asked about their level of confidence in their insurance coverage. Moreover, $51.3 \%$ of surveyed neurosurgeons reported no change in liability premiums over the last 3 years. However, $20 \%$ reported an increase and about $10 \%$ reported a decrease over the last 3 years (Table 4). The neurosurgeons were also asked what 
TABLE 1. Demographic characteristics of board-certified Canadian neurosurgeons

\begin{tabular}{|c|c|}
\hline Characteristic & Percentage \\
\hline \multicolumn{2}{|l|}{ Sex } \\
\hline Male & $85.2 \%$ \\
\hline Female & $9.4 \%$ \\
\hline Unreported & $5.4 \%$ \\
\hline \multicolumn{2}{|l|}{ Age in yrs } \\
\hline $21-29$ & $5.40 \%$ \\
\hline $30-39$ & $23 \%$ \\
\hline $40-49$ & $24.30 \%$ \\
\hline $50-59$ & $16.20 \%$ \\
\hline $60-69$ & $17.60 \%$ \\
\hline $70-79$ & $4 \%$ \\
\hline$>79$ & $2.70 \%$ \\
\hline Unreported & $6.70 \%$ \\
\hline \multicolumn{2}{|l|}{ Clinical status } \\
\hline In residency training & $16.20 \%$ \\
\hline In fellowship training & $5.40 \%$ \\
\hline$<5$ yrs in practice & $6.70 \%$ \\
\hline $5-10$ yrs in practice & $12.20 \%$ \\
\hline $10-20$ yrs in practice & $25.70 \%$ \\
\hline $20-30$ yrs in practice & $12.20 \%$ \\
\hline$>30$ yrs in practice & $14.90 \%$ \\
\hline Other (e.g., retired) & $6.70 \%$ \\
\hline \multicolumn{2}{|c|}{ No. of annual operative cases } \\
\hline$<50$ cases & $5.40 \%$ \\
\hline $50-100$ & $8.10 \%$ \\
\hline $100-200$ & $33.80 \%$ \\
\hline $200-300$ & $35.10 \%$ \\
\hline $300-400$ & $8.10 \%$ \\
\hline $400-500$ & $2.70 \%$ \\
\hline$>500$ & $2.70 \%$ \\
\hline Unreported & $4 \%$ \\
\hline \multicolumn{2}{|c|}{ No. of lifetime operative cases } \\
\hline$<500$ & $6.80 \%$ \\
\hline $501-1000$ & $14.90 \%$ \\
\hline $1001-2000$ & $16.20 \%$ \\
\hline $2001-3000$ & $10.80 \%$ \\
\hline $3001-4000$ & $13.50 \%$ \\
\hline $4001-5000$ & $6.80 \%$ \\
\hline $5001-10,000$ & $14.90 \%$ \\
\hline$>10,000$ & $12 \%$ \\
\hline Unreported & $4.1 \%$ \\
\hline
\end{tabular}

the appropriate malpractice premium should be annually, and around $70 \%$ agreed that it should not exceed $\$ 30,000$, but $2.7 \%$ found it still reasonable to pay up to $\$ 50,000$ for annual malpractice insurance (Table 4).

Almost $40 \%$ of the respondents reported that they have never been sued, and almost $20 \%$ were sued in the last 3 years (Table 5). Interestingly, $32.4 \%$ of surveyed neurosur-
TABLE 2. Characteristics of neurosurgical practices

\begin{tabular}{cc}
\hline \multicolumn{1}{c}{ Characteristic } & Percentage \\
\hline Type of practice & \\
\hline General & $45.90 \%$ \\
\hline Functional & $16.20 \%$ \\
\hline Trauma & $27 \%$ \\
\hline Cerebrovascular & $23 \%$ \\
\hline Tumor & $30 \%$ \\
\hline Spine & $43.20 \%$ \\
\hline Pediatrics & $25.70 \%$ \\
\hline Setting & \\
\hline Academic & $77 \%$ \\
\hline Academic affiliate & $10.8 \%$ \\
\hline Community & $10.8 \%$ \\
\hline Group practice & $22.9 \%$ \\
\hline Solo practice & $6.7 \%$ \\
\hline Retired & $6.7 \%$ \\
\hline No. of neurosurgeon colleagues & \\
\hline Solo practitioner & $4.10 \%$ \\
\hline $1-2$ & $5.40 \%$ \\
\hline $3-5$ & $21.6 \%$ \\
\hline $6-10$ & $18.90 \%$ \\
\hline$>10$ & $43.20 \%$ \\
\hline Unreported & $6.80 \%$ \\
\hline
\end{tabular}

geons said liability premiums affect where they practice, while the majority (48.7\%) said liability premiums do not affect their location of practice (Table 5).

Imaging and laboratory tests, which are examples of positive DM, were found to be the most practiced type $(85.2 \%)$ of DM. In total, $31.1 \%$ of respondents reported that they order imaging "sometimes" in order to avoid the potential risk of a lawsuit, and $35.1 \%$ admitted to ordering unnecessary laboratory tests. In addition, $43.2 \%$ of respondents referred patients that they saw as a potential lawsuit, which is an example of negative DM behavior. Neurosurgeons were also surveyed for what they would consider "high-risk" procedures. Head trauma and spine trauma were high on the list $(32.4 \%$ and $41.9 \%$, respectively). Epidural and subdural hematoma evacuations were moderately high $(24.3 \%$ and $25.7 \%$, respectively). Aneurysm coiling was not considered a high-risk procedure for lawsuits (8.1\%) (Table 5).

\section{Discussion}

Canada has a publicly funded, single-payer health care system: the majority of the funding comes from income taxes and federal subsidies, and all citizens are allowed access to health care coverage regardless of income. Each of Canada's provinces and territories runs its own insurance program, and these programs vary in terms of whether they cover supplementary services, such as dental coverage or prescription medication. Most citizens also take out private insurance plans to help cover these supplementary 
TABLE 3. Burden of liability

\begin{tabular}{|c|c|}
\hline Characteristic & Percentage \\
\hline \multicolumn{2}{|l|}{ Minimum coverage by institution } \\
\hline Not required & $32.4 \%$ \\
\hline Unknown & $47.3 \%$ \\
\hline$\$ 250,000-\$ 500,000$ & $1.4 \%$ \\
\hline$\$ 1-\$ 2$ million & $6.7 \%$ \\
\hline$>\$ 5$ million & $5.4 \%$ \\
\hline Unreported & $6.8 \%$ \\
\hline \multicolumn{2}{|l|}{ Cost of liability insurance } \\
\hline$<\$ 1000$ & $16.2 \%$ \\
\hline$\$ 1001-\$ 5000$ & $20.3 \%$ \\
\hline$\$ 5001-\$ 10,000$ & $4 \%$ \\
\hline$\$ 15,001-\$ 20,000$ & $6.1 \%$ \\
\hline$\$ 20,001-\$ 25,000$ & $13.5 \%$ \\
\hline$\$ 25,001-\$ 30,000$ & $9.4 \%$ \\
\hline$>\$ 30,000$ & $25.7 \%$ \\
\hline Unreported & $4.1 \%$ \\
\hline \multicolumn{2}{|c|}{ Percentage of income going to malpractice } \\
\hline$<5 \%$ & $64.9 \%$ \\
\hline $6-9 \%$ & $20.3 \%$ \\
\hline $10-19 \%$ & $5.4 \%$ \\
\hline $20-29 \%$ & $1.4 \%$ \\
\hline Unreported & $8.1 \%$ \\
\hline \multicolumn{2}{|l|}{ Burden of liability insurance } \\
\hline Not a burden & $52.7 \%$ \\
\hline Minor burden & $39.2 \%$ \\
\hline Major burden & $4.1 \%$ \\
\hline Unreported & $4.1 \%$ \\
\hline
\end{tabular}

services, and about $30 \%$ of health care financing comes from these private expenditures. ${ }^{3}$ Membership fees go toward covering insurance costs, although some provinces reimburse members for a portion of these costs: for instance, in 2008, Ontario reimbursed $83 \%$ of the insurance costs. ${ }^{6}$ About $95 \%$ of the country's physicians are members of the nonprofit Canadian Medical Protective Association (CMPA), which covers malpractice insurance for member physicians. ${ }^{12}$ Membership in the CMPA is financially encouraged by the Canadian government through contractual relationships between physician organizations and the provincial health authorities. In most cases, the malpractice fees paid to CMPA by physicians are reimbursed (usually less than \$1000). CMPA also provides legal defense to physicians facing lawsuits and pays any financial compensation to patients.

This study marks the first survey to identify the perceptions among Canadian neurosurgeons of DM practices and their potential impacts on health care delivery. Neurosurgeons from every Canadian province participated in the survey, with the majority of responses coming from Ontario (41.9\%). In total, $25.7 \%$ of our surveyed physicians had 10 to 20 years of experience in neurosurgery, and approximately one-third perform 200 to 300 operative cases
TABLE 4. Malpractice premiums

\begin{tabular}{|c|c|}
\hline Characteristic & Percentage \\
\hline \multicolumn{2}{|l|}{ Policy payout per occurrence } \\
\hline$<\$ 1$ million & $13.5 \%$ \\
\hline$\$ 1-\$ 3$ million & $5.4 \%$ \\
\hline$>\$ 3$ million & $39.7 \%$ \\
\hline Unreported & $41.4 \%$ \\
\hline \multicolumn{2}{|l|}{ Policy payout maximum } \\
\hline$<\$ 1$ million & $8.1 \%$ \\
\hline$\$ 1-\$ 3$ million & $2.7 \%$ \\
\hline$\$ 3-\$ 5$ million & $4.1 \%$ \\
\hline$>\$ 5$ million & $33.8 \%$ \\
\hline Unreported & $51.3 \%$ \\
\hline \multicolumn{2}{|l|}{ Level of confidence in policy coverage } \\
\hline Very confident & $74.3 \%$ \\
\hline Somewhat confident & $13.5 \%$ \\
\hline Not at all confident & $1.4 \%$ \\
\hline Unreported & $10.8 \%$ \\
\hline \multicolumn{2}{|c|}{ Change in liability premiums over the last 3 yrs } \\
\hline No significant change & $51.35 \%$ \\
\hline Decreased $>10 \%$ & $5.4 \%$ \\
\hline Decreased $>25 \%$ & $4.1 \%$ \\
\hline Increased $>10 \%$ & $14.9 \%$ \\
\hline Increased $>25 \%$ & $5.4 \%$ \\
\hline Unknown & $18.9 \%$ \\
\hline \multicolumn{2}{|c|}{ Average schedule of benefits change over last $3 \mathrm{yrs}$} \\
\hline No significant change & $62.2 \%$ \\
\hline Decreased $>10 \%$ & $4 \%$ \\
\hline Decreased $>25 \%$ & $4 \%$ \\
\hline Increased $>10 \%$ & $8.1 \%$ \\
\hline Increased $>25 \%$ & $1.4 \%$ \\
\hline Unknown & $20.3 \%$ \\
\hline \multicolumn{2}{|c|}{$\begin{array}{l}\text { Appropriate malpractice premium for neurosurgeons } \\
\text { (annually) }\end{array}$} \\
\hline$<\$ 5000$ & $13.5 \%$ \\
\hline$\$ 6000-\$ 10,000$ & $21.6 \%$ \\
\hline$\$ 11,000-\$ 20,000$ & $23 \%$ \\
\hline$\$ 21,000-\$ 30,000$ & $16.2 \%$ \\
\hline$\$ 31,000-\$ 40,000$ & $8.1 \%$ \\
\hline$\$ 41,000-\$ 50,000$ & $2.7 \%$ \\
\hline Unreported & $14.9 \%$ \\
\hline
\end{tabular}

annually (Table 1). Most of the respondents were Caucasian males.

The majority of neurosurgeons in Canada feel that their malpractice coverage is adequate-in fact, $74.3 \%$ were "very" confident in their malpractice coverage. In comparison, around 70\% of American neurosurgeons reported that they lack confidence in their current liability coverage, even though they pay as high as $15 \%$ of their annual income in insurance. ${ }^{14}$ The level of confidence is of great importance since Studdert et al. ${ }^{16}$ have demonstrated its 
TABLE 5. Lawsuits, medical liability, and practice of DM

\begin{tabular}{|c|c|}
\hline Characteristic & Percentage \\
\hline \multicolumn{2}{|l|}{ Previous lawsuit } \\
\hline Never sued & $39.2 \%$ \\
\hline$<3$ yrs ago & $18.9 \%$ \\
\hline$>3$ yrs ago & $31.1 \%$ \\
\hline Unreported & $10.8 \%$ \\
\hline \multicolumn{2}{|c|}{ Does medical liability affect where to practice? } \\
\hline Neutral & $10.8 \%$ \\
\hline Disagree & $25.7 \%$ \\
\hline Strongly disagree & $23 \%$ \\
\hline Agree & $27 \%$ \\
\hline Strongly agree & $5.4 \%$ \\
\hline Unreported & $8.1 \%$ \\
\hline \multicolumn{2}{|c|}{ Orders to minimize the risk for a lawsuit } \\
\hline Ordered laboratory tests & $35.1 \%$ \\
\hline Referred patients & $43.2 \%$ \\
\hline Prescribed medication & $9.4 \%$ \\
\hline Suggested a procedure & $9.4 \%$ \\
\hline Ordered imaging & $50.1 \%$ \\
\hline Discussion w/ patient & $1.4 \%$ \\
\hline \multicolumn{2}{|l|}{ Order additional imaging } \\
\hline Very often & $12.2 \%$ \\
\hline Sometimes & $31.1 \%$ \\
\hline Rarely & $37.8 \%$ \\
\hline Never & $13.5 \%$ \\
\hline Unreported & $5.4 \%$ \\
\hline \multicolumn{2}{|l|}{ Conduct initial consultation } \\
\hline Very often & $2.7 \%$ \\
\hline Sometimes & $25.7 \%$ \\
\hline Rarely & $35.1 \%$ \\
\hline Never & $28.4 \%$ \\
\hline Unreported & $8.1 \%$ \\
\hline \multicolumn{2}{|l|}{ High-risk procedures for lawsuits } \\
\hline Shunts (pediatrics) & $18.9 \%$ \\
\hline Spine trauma & $41.9 \%$ \\
\hline Workers' compensation injury & $33.8 \%$ \\
\hline Head trauma & $32.4 \%$ \\
\hline Subdural evacuation & $25.7 \%$ \\
\hline Epidural evacuation & $24.3 \%$ \\
\hline Aneurysm coiling & $8.1 \%$ \\
\hline Aneurysm clipping & $20.3 \%$ \\
\hline Tumor resection & $28.4 \%$ \\
\hline
\end{tabular}

significant role as a predictor of DM practice along with the physician's perception of premium burden, which was found to be a major issue only in $4.1 \%$ of our surveyed Canadian neurosurgeons. Accordingly, more than $30 \%$ of our respondents pay less than $\$ 5000$ USD in insurance annually. Many of these surgeons are likely the beneficiaries of the abovementioned reimbursement arrangement between physician organizations and provincial health au- thorities. Only 1 in 5 respondent Canadian neurosurgeons (21.8\%) reported viewing patients as potential plaintiffs. Our survey results clearly support Studdert et al.'s conclusions, and it is reasonable to say that DM is not practiced as frequently in Canada as it is in the US.

Regarding DM behaviors, the practice of ordering additional imaging is relatively low (37.8\%) in Canada, though most of the doctors practicing DM agreed that laboratory tests and imaging are the most common practices of DM (Table 5). This finding corroborates previous reports. For example, a New York-based study found that up to 59\% of those ordering imaging for head trauma are driven by the desire to minimize the possibility of malpractice litigation. ${ }^{7}$ In general, there was little reported fear regarding potential lawsuits. In total, $39.2 \%$ of the surveyed doctors reported that they have never been sued, and only $32.4 \%$ agreed that the medical liability system affects where they practice.

DM practices in the US tend to predominate in highrisk specialties such as obstetrics, neurosurgery, and orthopedic surgery. ${ }^{2,16}$ Rovit et al. explored neurosurgical experiences with malpractice litigation in the US in 2007 and found that neurosurgeons are at high risk of litigation. ${ }^{11}$ They examined practice patterns and resultant litigation in a major physician-owned and -administered insurance company over a 5 -year period (the largest physician-owned mutual insurance company in the US, which is based in the state of New York). In terms of total indemnity paid out by the insurance company over the 5-year period, neurosurgery ranked 10th out of 10 specialties with $\$ 60,000,000$. Obstetrics was the highest with $\$ 450,000,000$ paid out over 5 years. ${ }^{11}$ However, when the indemnity figures were weighted by the actual numbers of insured specialists, neurosurgery was found to be the most vulnerable specialty, with more than $\$ 600,000$ paid out per neurosurgeon over the study period. This figure was twice as much as the next highest specialty, obstetrics. ${ }^{11}$ In addition, about half of evaluated neurosurgeons had at least 1 suit filed against them over the past 5 years, and almost one-quarter had 2 suits filed against them. This type of data helps to demonstrate why neurosurgery as a specialty pays enormous insurance premiums in the US. The authors point out that not only are the awarded economic and noneconomic damages exceedingly high in some states in the US, but also the risk is spread out over a very small risk pool. Neurosurgeons in some states in the US pay up to $\$ 400,000$ annually for medical liability insurance. On the other hand, in Toronto, a neurosurgeon pays roughly $\$ 29,200$ for insurance coverage. These numbers are even smaller in other cities in other provinces, such as Montreal, where a neurosurgeon only pays $\$ 20,600$ for insurance, and Vancouver where the insurance premium is $\$ 10,650{ }^{9}$

There are several leading hypotheses as to why DM is not practiced as frequently in Canada. In 1978, the Canadian Supreme Court limited the cap amount that can potentially be paid out for noneconomic financial compensation to $\$ 300,000$; the US, on the other hand, has no such federal restriction. ${ }^{6}$ Some patients might not find it worthwhile to go through the trouble of suing their physicians and challenging the CMPA for a relatively small sum, the majority of which will actually go toward paying off the 
patient's legal teams and administrative costs instead of the patients themselves.

Unlike US law firms, Canadian law firms typically require the plaintiffs to pay for the initial investigation in order to determine whether a potential lawsuit even has merit-such costs also deter patients from making claims. Additionally, due to the single-payer system in Canada, the CMPA aggressively - and often successfully-defends its members in court, often spending significant amounts of money for their defense. Of all the cases tried in 2007, the patient won roughly 25 times and the physician won roughly 70 times. The median amount of damages awarded was $\$ 91,000$, a relatively small sum in comparison with the hundreds of millions of dollars that could potentially be awarded in a case in the US.9

Furthermore, in Canada, the burden of proof lies with the plaintiff, who must prove negligence and not simply an error in judgment on the part of the physician. The losing party must also pay approximately two-thirds of the winning party's costs, another disincentive for filing a lawsuit. ${ }^{6}$ In the Canadian system, these deterrents to filing lawsuits could mean that physicians do not fear being sued as greatly and, as a result, they are less likely to order unnecessary tests and procedures.

The medicolegal environments between the US and Canada are so different that in 2004 the CMPA declared it will no longer insure Canadian physicians who treat American patients using elective procedures due to the litigation risks. ${ }^{8}$

Lastly, and in contrast to the US, the majority of Canadian neurosurgeons practice in groups of 5 or more practitioners or in large academic settings. This study attempted to evaluate the differences in DM practice between neurosurgeons in large, academic groups and neurosurgeons in individual practices, but unfortunately only 6 neurosurgeons who responded to the survey reported practicing in a solo private practice. We were therefore unable to establish a statistically significant difference in DM behavior between these 2 groups.

It is clear that American physicians order more tests than their Canadian counterparts-this DM practice led to an increase in health care costs by $9 \%$ in 2005 . The Canadian health care system works well, as evidenced by Canadians' longer life expectancies, and keeps health care costs down. ${ }^{1}$ However, the Canadian system is not without faults - the wait times in Canada are significantly longer than they are in the US, and access to new medical technologies may lag behind. ${ }^{5}$ It remains to be seen whether the US will adopt a similar approach to the Canadian health care system or implement any changes in its litigation-centric system to combat DM practices and keep health care costs down.

\section{Limitations}

DM is a concept shaped by physician beliefs, and these are notoriously difficult to measure. In fact, the perfect measurement of DM would be counterfactual. The motivation to order an additional test is inherently related to the physician's confidence, experience, reimbursement, and perception of legal risk.

Moreover, this study is a cross-sectional survey of phy- sician perceptions of DM and is susceptible to bias. Unfortunately, there was no opportunity to compare basic demographic features between respondents and nonrespondents in order to find out whether our study represents the actual DM practice in Canada. Also, this study provides information at a certain point in time; a series of surveys could demonstrate more clearly how practitioners view and report their DM practices. The survey was completed anonymously, and no incentives were provided upon survey completion. Selection bias occurred if the survey sample did not accurately represent the population. Nonresponse bias is also a concern. Voluntary response bias tends to overrepresent those who have strong opinions.

\section{Conclusions}

Canadian neurosurgeons perceive their medicolegal risk environment to be favorable, their patients as unlikely to sue, and overall engage infrequently in DM behaviors.

\section{References}

1. Bezruchka S: Societal hierarchy and the health Olympics. CMAJ 164:1701-1703, 2001

2. Bishop TF, Federman AD, Keyhani S: Physicians' views on defensive medicine: a national survey. Arch Intern Med 170:1081-1083, 2010

3. Canadian Institute for Health Information: National Health Expenditure Trends, 1975 to 2014. Ottawa: Canadian Institute for Health Information, 2014

4. Dubay L, Kaestner R, Waidmann T: The impact of malpractice fears on cesarean section rates. J Health Econ 18:491522,1999

5. Eisenberg MJ: An American physician in the Canadian health care system. Arch Intern Med 166:281-282, 2006

6. Law Library of Congress: Comparative Summary: Medical Liability in Selected Countries. (http://www.loc.gov/law/ help/medical-malpractice-liability/medical-liability.pdf ) [Accessed August 28, 2015]

7. Lawthers AG, Localio AR, Laird NM, Lipsitz S, Hebert L, Brennan TA: Physicians' perceptions of the risk of being sued. J Health Polit Policy Law 17:463-482, 1992

8. Lougheed T: Cross-border malpractice coverage cancelled. CMAJ 171:438, 2004

9. Martin ST: Canada keeps malpractice cost in check. Tampa Bay Times. July 26, 2009. (http://www.tampabay.com/news/ canada-keeps-malpractice-cost-in-check/1021977) [Accessed August 28, 2015]

10. Reynolds RA, Rizzo JA, Gonzalez ML: The cost of medical professional liability. JAMA 257:2776-2781, 1987

11. Rovit RL, Simon AS, Drew J, Murali R, Robb J: Neurosurgical experience with malpractice litigation: an analysis of closed claims against neurosurgeons in New York State, 1999 through 2003. J Neurosurg 106:1108-1114, 2007

12. Silversides A: Fault/no fault, part 3: Vested interests and the silence of suffering patients cited as obstacles to system change. CMAJ 179:515-517, 2008 (Erratum in CMAJ 179:932, 2008)

13. Sloan FA, Shadle JH: Is there empirical evidence for "defensive medicine"? A reassessment. J Health Econ 28:481-491, 2009

14. Smith TR, Habib A, Rosenow JM, Nahed BV, Babu MA, Cybulski G, et al: Defensive medicine in neurosurgery: does state-level liability risk matter? Neurosurgery 76:105-114, 2015

15. Studdert DM, Mello MM, Brennan TA: Medical malpractice. N Engl J Med 350:283-292, 2004 
16. Studdert DM, Mello MM, Sage WM, DesRoches CM, Peugh J, Zapert K, et al: Defensive medicine among high-risk specialist physicians in a volatile malpractice environment. JAMA 293:2609-2617, 2005

17. Tancredi LR, Barondess JA: The problem of defensive medicine. Science 200:879-882, 1978

18. Woodward CA, Rosser W: Effect of medicolegal liability on patterns of general and family practice in Canada. CMAJ 141:291-299, 1989

\section{Disclosures}

The authors report no conflict of interest concerning the materials or methods used in this study or the findings specified in this paper.

\section{Author Contributions}

Conception and design: Smith, Babu, Das, Gormley, Rutka, Laws, Heary. Acquisition of data: Smith, Cote, Nahed, Babu,
Das, Gormley, Rutka, Heary. Analysis and interpretation of data: Smith, Hulou, Nahed, Rutka. Drafting the article: Smith, Hulou, Yan. Critically revising the article: Smith, Hulou, Yan, Cote, Rutka, Laws, Heary. Reviewed submitted version of manuscript: all authors. Approved the final version of the manuscript on behalf of all authors: Smith. Statistical analysis: Smith, Hulou. Administrative/technical/material support: Hulou. Study supervision: Smith.

\section{Supplemental Information}

\section{Online-Only Content}

Supplemental material is available with the online version of the article.

Appendix. http://thejns.org/doi/suppl/10.3171/2015.6.JNS15764.

\section{Correspondence}

Timothy R. Smith, Department of Neurosurgery, Brigham and Women's Hospital, 15 Francis St., PBB3, Boston, MA 02115. email: trsmith@partners.org. 